\title{
PARÂMETROS ANATÔMICOS, MORFOLÓGICOS E FISIOLÓGICOS DE FORRAGEIRAS CULTIVADAS EM SISTEMA AGROSSILVIPASTORIL: UMA REVISÃO
}

\author{
Kárito Augusto Pereira* \\ Arnon Henrique Campos Anésio** \\ Ulisses Gabriel Moraes Lobo**** \\ Anderson Rodrigues de Oliveira**** \\ Jessica Caetano Dias Campos ${ }^{* * * * *}$
}

RESUMO: Objetivou-se, com essa literatura, descrever de maneira sucinta os parâmetros referentes à morfologia, anatomia e fisiologia de plantas forrageiras cultivadas em sistema agrossilvipastoril, correlacionando com os principais mecanismos de produção. Através da avaliação das alterações morfológicas, anatômicas e fisiológicas que ocorrem em plantas sob irradiância reduzida pode acarretar seleção de espécies forrageiras mais adaptadas ao meio, demonstrando a importância significativa dos sistemas agrossilvipastoris que podem ser considerados soluções para problemas relacionados à conservação dos recursos naturais e forma sustentável de utilização das pastagens de baixa fertilidade natural. Os sombreamentos existentes nestes sistemas influenciam o crescimento da forrageira e modificam suas características agronômicas reduzindo o número de perfilhos, porém para trazer benefícios à pastagem, desde que o sombreamento seja moderado. Então pode ser constatado que plantas forrageiras cultivadas em sistemas agrossilvipastoris, em baixa luminosidade, conservam seus estômatos abertos, a fim de aumentar o escoamento dos gases para a realização da fotossíntese. De maneira geral, plantas forrageiras de clima tropical submetidas ao sombreamento apresentam grande vantagem de adaptações morfológicas, anatômicas e fisiológicas com elevados índices de produção de forragem.

PALAVRAS-CHAVE: Área foliar; Estômatos; Fotossíntese; Sombreamento.

\footnotetext{
Zootecnista. Mestrando em Zootecnia pela Universidade Federal dos Vales do Jequitinhonha e Mucuri (UFVJM), Departamento de Zootecnia. Minas Gerais. Brasil. E-mail: karitoaugusto@hotmail.com

** Zootecnista. Mestre em Zootecnia pela Universidade Federal dos Vales do Jequitinhonha e Mucuri (UFVJM), Departamento de Zootecnia. Minas Gerais. Brasil

${ }^{* * *}$ Zootecnista. Departamento de Zootecnia. Goiás, Brasil

**** Zootecnista. Mestrando em Zootecnia pela Universidade Federal dos Vales do Jequitinhonha e Mucuri (UFVJM), Departamento de Zootecnia. Minas Gerais. Brasil

***** Zootecnista. Mestranda em Engenharia Agrícola pela Universidade Estadual de Goiás (UEG) - Câmpus de Anápolis Henrique Santillo. Goiás. Brasil
} 


\title{
ANATOMIC, MORPHOLOGIC AND PHYSIOLOGICAL PARAMETERS OF FORAGERS IN AGRO-SILVIPASTORAL SYSTEM: A REVIEW
}

\begin{abstract}
Morphologic, anatomic and physiological parameters of forage plants cultivated in agro-silvipastoral systems and correlated with the main production mechanisms are briefly described. The selection of forager species, more adapted to the environment, may be provided by evaluating morphologic, anatomic and physiological changes in plants with reduced irradiance. The above reveals the significant importance of agro-silvipastoral systems as possible solutions for issues related to the conservation of natural resources and sustainable manner of using pastures with low fertility. Shades in the systems affect the growth of foragers and modify their agronomic characteristics by reducing the number of leaves. However, pastures may be improved when shade is moderate. Forager plants cultivated in agro-silvipastoral systems, with low luminosity, conserve open their stomata with an increase of gas discharge for photosynthesis. As a rule, tropical forager plants submitted to shade have a great advantage in morphologic, anatomic and physiological adaptations, with high forage production indexes.
\end{abstract}

KEY WORDS: Leaf area; Stomata; Photosynthesis; Shade.

\section{INTRODUÇÃO}

No Brasil, cerca de $20 \%$ da área territorial é ocupada por pastagens, próximas a 181 milhões de hectares, sendo responsável por ter a segunda maior produção de carne bovina no mundo (WEDEKIN, 2017). Entretanto, atualmente estima-se que $80 \%$ das pastagens cultivadas encontram-se em algum estágio de degradação devido à escolha de espécies forrageiras inadequadas, formação de pastagem e manejo incorretos (FAO, 2014).

A degradação das pastagens é um dos maiores problemas da pecuária no Brasil, uma vez que é a atividade econômica que mais faz uso dos recursos naturais do planeta (WEDEKIN, 2017), entretanto, podem ser evitadas ou recuperadas com o uso de tecnologias de produção como os sistemas integrados de silvipastoril e agrossilvopastoril que permitem, dentro de uma perspectiva de desenvolvimento sustentável, a mitigação de seus impactos ambientais tradicionais da atividade pe- 
cuária, permitindo aumento da biodiversidade, uso conservacionista do solo e da água (OLIVEIRA; MANESCHY, 2009).

O uso dessas técnicas que implicam de modo simultâneo da terra para fins de produção agrícola, florestal e pecuária tem demonstrado ser uma alternativa para promover a sustentabilidade do sistema de produção (CASTRO et al., 2009). Assim, os sistemas agroflorestais que incluem o sistema silvipastoril que utiliza a combinação de árvores, pastagem e gado na mesma área e ao mesmo tempo, manejados de forma integrada. Ademais, o sistema agrossilvipastoril, o qual constitui em integrar lavouras, com espécies florestais, pastagens e animais (DIAS-FILHO, 2006). Concomitantemente, produzir madeira, estacas, postes, mourões, lenha e outros (OLIVEIRA; MANESCHY, 2009).

A referida associação traz diversos benefícios como a melhoria da fertilidade do solo e auxílio no controle de erosões, além de manter o solo produtivo, pois eleva o teor de matéria orgânica, aumenta a diversidade dos organismos do solo, além de elevar o acúmulo e estabilização de C no mesmo (BOTREL et al., 2002). Por isso, há necessidade de se aprofundar no conhecimento referente à morfologia, anatomia, e fisiologia vegetal das espécies forrageiras submetidas ao sombreamento, visto que exigem uma atenção especial na relação dos diferentes vegetais com os diversos manejos, já que o corpo do vegetal está dinamicamente relacionado com essas práticas de manejo.

Essas características representam o entendimento adequado dos efeitos de variação nas condições da forragem sobre o desempenho, tanto da planta, como do animal, e da resposta de ambos ao manejo que será adotado, somente poderá ser atingido quando se conduzir estudos baseados no controle de características do pasto, a fim de estabelecer uma estratégia ideal de manejo de pastagem (MARTUSCELLO, 2004).

Portanto, objetivou-se, a partir desta revisão, descrever de maneira sucinta parâmetros morfológicos, anatômicos, e fisiológicos de forrageiras cultivadas em sistemas agrossilvipastoris, correlacionando com os principais mecanismos de produção. 


\section{REVISÃO DA LITERATURA}

\subsection{ASPECTOS MORFOLÓGICOS DE FORRAGEIRAS EM SISTEMAS AGROSSILVI- PASTORIS}

As plantas que são submetidas a estresse de calor durante o verão adquirem mecanismos morfológicos que possibilitam sua sobrevivência, compreendendo a redução do tamanho da folha, capacidade de enrolamento, alta densidade de tricomas, estômatos profundos, acúmulo de mucilagem e outros metabólitos secundários além do aumento da compactação do mesófilo (BOSABALIDIS; KOFIDIS, 2002).

Contudo, plantas submetidas ao sombreamento de forma natural ou, até mesmo de forma artificial, investem principalmente em maior proporção de fotoassimilados no aumento da área foliar, para maximizar a captação da luz que é fornecida, resultando em modificações significativas na morfologia de muitas espécies forrageiras, se caracterizando por apresentarem folhas delgadas, com maior área foliar específica e menor densidade de massa (LAMBERS; CHAPIM; PONS, 1998).

$\mathrm{O}$ aumento da área foliar sem dúvidas é uma das principais adaptações morfológicas das plantas para compensar reduções na radiação incidente, que precisa ser ajustada ao acúmulo suficiente de reservas e também na manutenção da população de plantas na área. Visto que, abaixo dos níveis de radiação incidente determinados, prejudica o acúmulo de carboidratos através da redução da capacidade fotossintética, limitando a expansão foliar (PERI; LUCAS; MOOT, 2007).

Garcez Neto et al. (2010), avaliando características morfológicas de lolium perenne cv. Nui, actylis glomerata cv. vision e trifolium pratense cv. Pawera em quatro níveis de 0, 25, 50 e 75\% de sombreamento, em dois padrões (contínuo e alternado), sob três períodos de crescimento (estabelecimento, primeira e segunda rebrotação), identificaram que a maioria das medidas morfológicas foram afetadas pelos níveis de sombreamento. Visto que, as adaptações morfológicas do dátilo foram as que mais se relacionaram à tolerância ao sombreamento, já a expansão da área foliar individual apenas ocorreu com o azevém-perene, concluindo que a faixa de sombreamento entre 25 e $50 \%$ pode ser considerada a de maior aclimatação morfológica das forrageiras para compensar a restrição luminosa. 
Resultados semelhantes foram obtidos por Peri; Lucas; Moot (2007), utilizando folhas de dátilo submetidas a intenso sombreamento, aumentam em $33 \%$ o comprimento da lâmina foliar, entretanto a largura da lâmina foliar pode reduzir em até $22 \%$.

Andrade et al. (2003), avaliando o desempenho de seis gramíneas forrageiras consorciadas ou não com a leguminosa em um sistema silvipastoril, após dois ciclos de pastejo, observaram redução da proporção da leguminosa no consórcio com todas as gramíneas, sendo mais evidente com as mais agressivas como a $B$. brizantha cv. Marandu e $B$. decumbens. O maior desempenho produtivo foi obtido pelas gramíneas $B$. brizantha cv. Marandu, $B$. decumbens e sobretudo $P$. maximum cv. Mombaça quando consorciada com o estilosante Mineirão.

Dias et al. (2008) avaliaram mudas sem proteção usadas principalmente em cercas ou estacas, a partir de quatro espécies de leguminosas arbóreas, utilizadas em pastagens de Brachiaria brizantha cv. Marandu e Panicum maximum cv. Tanzânia, com a Mimosa artemisiana apresentaram maior altura e sobrevivência em pasto de capim-marandu.

Durante as estações do ano avaliando características morfogênicas, estruturais e a produção de matéria seca de Brachiaria decumbens cultivada a três níveis de sombreamento, demonstrando que eleva o alongamento de folhas e colmos, bem como o comprimento final das lâminas foliares quando submetidas ao sombreamento, mas não influencia a taxa de aparecimento de folhas e o número de folhas vivas por perfilho da Brachiaria decumbens, garantindo a essa espécie forrageira grande potencial para o seu uso em sistemas silvipastoris (PACIULLO et al., 2008).

Em sistema agrossilvipastoril Paciullo et al. (2011) identificaram que este mecanismo de alongamento foliar não foi capaz de manter a produtividade do pasto quando a gramínea foi exposta ao sombreamento intenso e até seis metros do renque de árvores.

Do mesmo modo, comparando o comportamento e produção de onze forrageiras perenes de verão, sob diferentes sombreamentos pelas árvores Pinus taeda, Soares et al. (2009) identificaram que as espécies Brachiaria brizantha cv. Marandu e Axonopus catharinensis apresentaram produção satisfatória e adaptação ao sombreamento sendo indicadas pelo seu potencial a comporem sistemas Silvi- 
pastoris. Por isso, a redução da densidade populacional de perfilhos da Brachiaria decumbens cultivada a três níveis de sombreamento é compensada pelo aumento nas taxas de alongamento de folhas e colmos, em condições de sombreamento mais intenso, o que também proporciona maior produção de matéria seca à sombra (PACIULLO et al., 2008).

Visto que a Brachiaria decumbens, sob sombreamento moderado com $35 \%$ de sombra, apresenta produção de forragem equivalente ou suplanta aquelas vistas a pleno sol, com aumentos de 65, 125 e 95\% para massa de forragem, índice de área foliar e densidade de perfilhos, proporcionado pela retirada de algumas árvores no sistema, possibilitando maior entrada de luz no sistema silvipastoril (PACIULLO et al., 2007). Sobretudo, no trabalho realizado por Paciullo et al. (2008), em que identificaram que o aparecimento de novos perfilhos ficou prejudicado com o sombreamento intenso de 50\%, apresentando menores valores no inverno, 224 perfilhos $/ \mathrm{m}^{2}$, destacando a importância da luminosidade na densidade populacional de perfilhos. Resultados também encontrados por Paciullo et al. (2007), em que verificaram a menor densidade de perfilhos, principalmente no primeiro ano de avaliação quando a gramínea foi exposta ao sombreamento de $65 \%$, apresentando 253 perfilhos $/ \mathrm{m}^{2}$ em comparação a sol pleno no mesmo ano, com 534 perfilhos $/ \mathrm{m}^{2}$.

A redução excessiva de luz solar no sistema floresta-pecuária diminuiu no capim Brachiaria decumbens $\mathrm{cv}$. Basilisk a densidade populacional de perfilho em $50 \%$ reduzindo sua massa foliar em 61\% e de colmos em 33\% quando comparados aos valores a pleno sol (SILVA et al., 2011, contrastando com os resultados encontrados por Martuscello et al. (2009), onde as espécies de Brachiaria (Basilisk, Marandu, Xaráes) obtiveram maior número de perfilhos por planta no cultivar Basilisk (21,74, $17,87,8,08)$ em todos os sombreamentos $(0 \%, 50 \%, 70 \%)$ respectivamente, quando comparado aos outros cultivares Marandu $(13,84,9,80,6,20)$ e Xaráes $(12,90,10,90$, $6,16)$, respectivamente, porém, não refletiu na produtividade.

Em seu trabalho, Wendling (2011) também encontrou menor densidade populacional de perfilhos na gramínea $B$. decumbens em consorciação com árvores de 375 e 458 perfilhos $/ \mathrm{m}^{2}$ em consórcio com eucalipto e 374 e 520 perfilhos $/ \mathrm{m}^{2} \mathrm{com}$ eucalipto e acácia no período do outono/inverno e primavera/verão, respectivamente. Já a Brachiaria cultivada solteira apresentou número de perfilho por $\mathrm{m}^{2} \mathrm{de} 663$ 
e 953 no período do outono/inverno e primavera/verão, respectivamente, podendo ser explicado pela interceptação da radiação solar do componente arbóreo.

Todavia Oliveira e Souto (2001) consideram que espécies de B. brizantha quando submetidas ao sombreamento não sofrem interferências se mostrando indiferentes à sombra com produção de matéria seca das hastes e das folhas. Entretanto, as mudanças estruturais do dossel das folhas mais baixas se dão a partir de uma disposição plana para uma disposição perpendicular.

Do mesmo modo, Conforto et al. (2011), analisando folhas sombreadas de sete clones adultos de seringueira, implantado na Agência Paulista de Tecnologia dos Agronegócios (APTA) - Polo Regional do Noroeste Paulista puderam identificar que os teores de clorofila total e de carotenóides totais foram de 3,14 e 1,04 $\mathrm{mg} \mathrm{g}^{-1}$ de peso fresco, respectivamente, sendo superiores ou iguais ao da testemunha. Já para a espessura foliar a média foi de $119,62 \mu \mathrm{m}$ e mostrou grande variação entre os clones IAC, com área foliar média de $219,17 \mathrm{~cm}^{2}$.

A produção de biomassa relacionada com as características estruturais do capim-andropogon em três idades de rebrota e em três ambientes de um sistema silvipastoril, utilizando também sob a copa de pau-d'arco, sob a copa de jatobá, em área aberta, local fora da copa de qualquer árvore e em sistema de monocultura, observa-se que o sombreamento quando submetido ao sistema silvipastoril, a partir da copa de paud'arco e de jatobá, e em área aberta não interfere negativamente na produção de matéria seca do capim-andropogon, entretanto reduz o percentual de folhas na massa de forragem do capim aos 35 dias, mas não afeta a rebrota da forrageira aos 49 e 63 dias (VERAS et al., 2010).

Contudo, observando a produtividade e as características biométricas do capim braquiária em pastejo, sob o sistema silvipastoril utilizando árvores nativas de interesse comercial, plantadas em fileiras, espaçados por $17 \mathrm{~m}$, conclui-se que a produtividade de forragem, nos dois primeiros ciclos de produção, e o índice de área foliar, no segundo e terceiro ciclo, diminuíram a partir dos níveis de sombra acima de 39 e 40\%, respectivamente. Entretanto a altura de plantas aumentou com sombreamentos superiores a 53\%, nos quatro primeiros ciclos, o que também ocorreu com a área foliar específica, com sombreamento superior a $66 \%$, nos três primeiros ciclos do sistema de produção silvipastoril (BOSI et al., 2014). 
Diante de tal fato, a exploração quando bem sucedida em sistemas silvipastoris requer o uso de espécies forrageiras tolerantes às condições de baixa luminosidade, a fim de apresentar adaptações que possam garantir sua sobrevivência e produção satisfatória (GOBBI et al., 2011).

Do mesmo modo, deve-se atentar que as arbóreas que possuam crescimento inicial rápido, copa reduzida e capacidade de regeneração, são preferenciais para compor os sistemas silvipastoris, devido a estas características têm seu estabelecimento facilitado, pois causam sombreamento menor sobre a pastagem e as mortes por danificações minimizadas (DIAS-FILHO, 2006).

Quadro 1. Levantamento sobre os estudos realizados referentes à morfologia de forrageiras submetidas ao sombreamento (Continua)

\begin{tabular}{|c|c|c|}
\hline Autores (morfologia) & Estudos & Conclusões \\
\hline $\begin{array}{l}\text { (OLIVEIRA; SOUTO, 2001); (BOSABALIDIS; } \\
\text { KOFIDIS, 2002); (LAMBERS; CHAPIM; } \\
\text { PONS, 1998); (PERI; LUCAS; MOOT, 2007); } \\
\text { (GARCEZ NETO et al., 2010); (PACIULLO } \\
\text { et al., 2008); (PACIULLO et al., 2007); (VE- } \\
\text { RAS et al., 2010); (PACIULLO et al., 2011); } \\
\text { (CONFORTO et al., 2011); (BOSI et al., } \\
\text { 2014) }\end{array}$ & Área foliar & $\begin{array}{l}\text { Aumento da área foliar para } \\
\text { maximizar a captação da luz }\end{array}$ \\
\hline $\begin{array}{l}\text { (BOSABALIDIS; KOFIDIS, 2002); (SILVA et } \\
\text { al., 2005); (CONCENÇO et al., 2008) }\end{array}$ & Estômatos & $\begin{array}{l}\text { Sob o sombreamento tor- } \\
\text { nam-se mais superficiais, com } \\
\text { alterações no tamanho, distri- } \\
\text { buição e forma }\end{array}$ \\
\hline $\begin{array}{l}\text { (OLIVEIRA; SOUTO, 2001); (BOSABALIDIS; } \\
\text { KOFIDIS, 2002); (LAMBERS; CHAPIM; } \\
\text { PONS, 1998); (PACIULLO et al., 2007); (PA- } \\
\text { CIULLO et al., 2008); (VERAS et al., 2010); } \\
\text { (SILVA et al., 2011); (BOSI et al., 2014) }\end{array}$ & $\begin{array}{l}\text { Produtividade da } \\
\text { forragem }\end{array}$ & $\begin{array}{l}\text { Maior densidade de massa em } \\
\text { sombreamento moderado. } \\
\text { Em sombreamento acima de } \\
50 \% \text { resulta em redação da } \\
\text { massa foliar }\end{array}$ \\
\hline $\begin{array}{l}\text { (ANDRADE et al., 2003); (PACIULLO et al., } \\
\text { 2007); (DIAS et al., 2008); (PACIULLO et al., } \\
\text { 2008); (SOARES et al., 2009); (MARTUSCE- } \\
\text { LLO et al., 2009); (PACIULLO et al., 2011); } \\
\text { (SILVA et al., 2011); (BOSI et al., 2014) }\end{array}$ & $\begin{array}{l}\text { Forrageiras mais } \\
\text { adaptadas }\end{array}$ & $\begin{array}{c}\text { B. brizantha cv. Marandu e } B \text {. } \\
\text { decumbens }\end{array}$ \\
\hline $\begin{array}{l}\text { (PACIULLO et al., 2007); (MARTUSCELLO } \\
\text { et al., 2009); (DIAS et al., 2008); (GARCEZ } \\
\text { NETO et al., 2010); (PACIULLO et al., 2011); } \\
\text { (GOBBI et al., 2011) }\end{array}$ & $\begin{array}{l}\text { Nível de sombrea- } \\
\text { mento }\end{array}$ & $\begin{array}{l}\text { Faixa de sombreamento entre } \\
25 \text { e } 50 \% \text { pode ser conside- } \\
\text { rada a de maior aclimatação } \\
\text { morfológica forrageira }\end{array}$ \\
\hline
\end{tabular}


(Conclusão)

\begin{tabular}{|l|c|c|}
\hline Autores (morfologia) & Estudos & Conclusões \\
\hline $\begin{array}{l}\text { (PACIULLO et al., 2007); (PACIULLO et } \\
\text { al., 2008); (MARTUSCELLO et al., 2009); } \\
\text { (VERAS et al., 2010); (SILVA et al., 2011); } \\
\text { (WENDLING, 2011) }\end{array}$ & Perfilhos & $\begin{array}{c}\text { Redução do número de per- } \\
\text { filhos em sombreamentos } \\
\text { acima de 50\% }\end{array}$ \\
\hline (CONFORTO et al., 2011) & $\begin{array}{c}\text { Clorofila e } \\
\text { carotenóides }\end{array}$ & $\begin{array}{c}\text { Superiores ou iguais quando } \\
\text { equipada a sistema a pleno } \\
\text { sol }\end{array}$ \\
\hline
\end{tabular}

\subsection{ASPECTOSANATÔMICOSDEFORRAGEIRASEMSISTEMASAGROSSILVIPASTORIS}

A anatomia vegetal é o ramo da botânica destinado a estudar a estrutura interna das plantas, sua origem se confunde com a descoberta da célula em 1663 por Robert Hooke, quando utilizou células vegetais mortas que fazem parte da periderme dos caules e raízes em crescimento secundário. Tal estudo permite relacionar as diversas estruturas internas da planta com suas funções e assim verificar possíveis tendências adaptativas da planta aos diversos ambientes e entender a funcionalidade dos mecanismos fisiológicos dos vegetais. Além da utilização na verificação de possíveis semelhanças entre grupos com certo grau de parentesco e auxiliar o posicionamento taxonômico desses indivíduos (APPEZZATO-DA-GLORIA; CARMELLO-GUERREIRO, 2003).

Os sistemas agrossilvipastoris podem levar a modificações de características anatômicas das espécies envolvidas, como forma de adaptação ao sistema implantado, alterações na espessura da lâmina foliar (Figura 1) e parênquimas clorofilianos, modificações na proporção de tecidos de folhas, raízes e caules (NOBEL, 1980). 

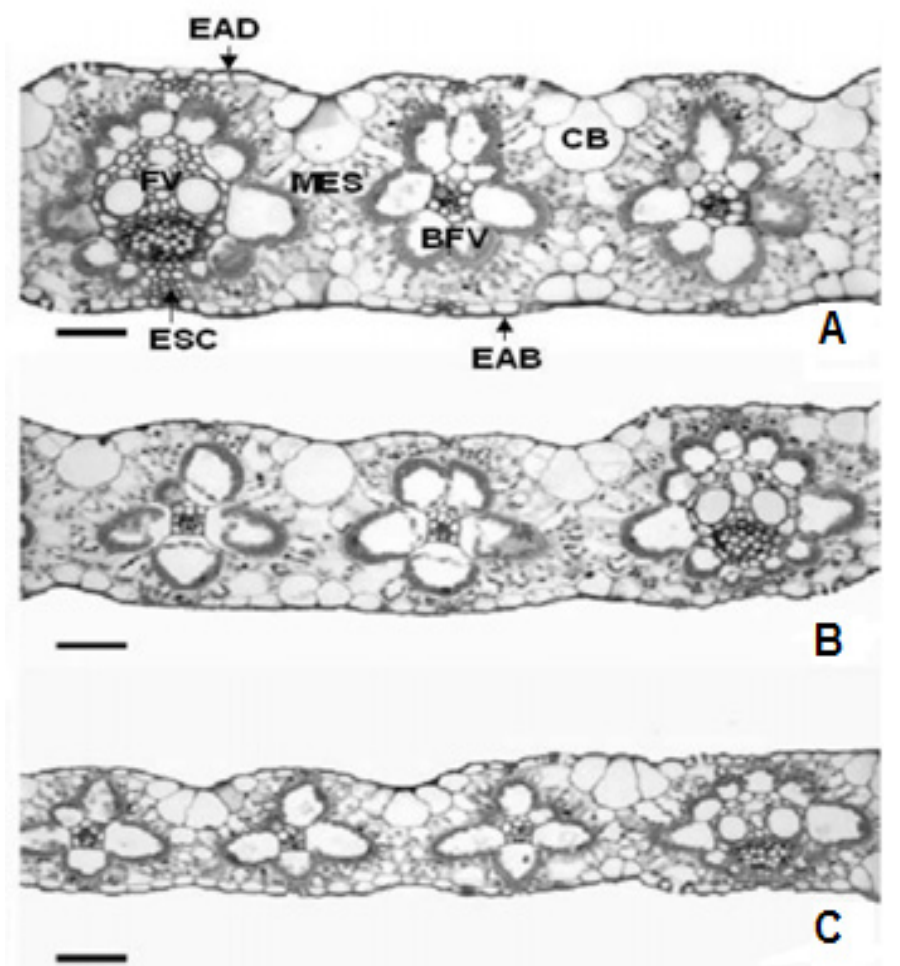

$* \mathrm{BFV}=$ bainha do feixe vascular; $\mathrm{CB}=$ célula buliforme; $\mathrm{CF}=$ idioblasto contendo compostos fenólicos; $\mathrm{EAB}=$ epiderme abaxial; $\mathrm{EAD}=$ epiderme adaxial; $\mathrm{ESC}=$ esclerênquima; $\mathrm{FV}=$ feixe vascular; $\mathrm{MES}=$ mesófilo; Barra $=50 \mu \mathrm{m}$.

Figura 1. Redução da espessura da folha a partir da seção transversal de folhas de Brachiaria decumbens Stapf. cv. Basilisk (A, B, C) submetidas a três níveis de sombreamento $(0,50$ e $70 \%$, respectivamente)

Fonte: Gobbi et al. (2011).

Por meio da anatomia vegetal é possível relacionar diversas estruturas internas da planta com suas funções, com o propósito de verificar possíveis tendências adaptativas da planta aos diversos ambientes e compreender seus mecanismos funcionais e fisiológicos (MARTUSCELLO, 2004).

Visto que as alterações anatômicas que ocorrem nas folhas que se desenvolvem em baixa luminosidade apresentam um papel muito importante na adaptação da planta sob condições impostas pelo ambiente (BERLYN; CHO, 2000).

Os aspectos histológicos referentes aos padrões anatômicos de plantas 
forrageiras, sobretudo na epiderme da folha, utilizam-se como amostras o tamanho e forma dos tricomas, presença ou ausência dos mesmos, ocorrência e posição das células suberosas e células silicosas a organização das células epidérmicas, além de orientação das nervuras, tipos de estômatos e inclusão de cristais (SILVA et al., 2005).

Resultados encontrados por Silva et al. (2005) demonstram que forrageiras submetidas ao primeiro sinal de calor intenso mantêm seus estômatos fechados, e pode ocorrer um acréscimo de $50 \%$ do número de estômatos, mas com redução acentuada de tamanho devido a dessecação do protoplasma.

As alterações anatômicas estão relacionadas com o aumento da captação e aproveitamento da luz incidente, pois, se trata de um recurso que limita o crescimento na sombra, proporcionando a eficiência fotossintética da planta (LAMBERS; CHAPIM; PONS, 1998).

Vale ressaltar que a anatomia foliar é extremamente capacitada para a absorção de luz a partir das propriedades do mesófilo e do parênquima paliçádico que proporcionam a absorção uniforme de luz através das folhas. Há também o movimento dos cloroplastos nas células sendo encontrados principalmente na epiderme dos órgãos aéreos em forrageiras de ambientes sombreados e a disposição da lâmina foliar em relação ao sol maximizando a absorção de luz (TAIZ; ZEIGER, 2009).

Pois, pigmentos distintos absorvem radiação em comprimentos de onda específicos, e desenvolvem nos vegetais uma série de respostas moduladas por eles, como alterações na anatomia e diferenciação de tecidos, desenvolvimento do aparato fotossintético, acúmulo de carboidrato nas folhas, alongamento de plantas, alteração nas concentrações de hormônios vegetais e inibição ou estímulo de brotações axilares (DIGNART et al., 2009).

O aumento da área foliar específica em condições de baixa luminosidade em forrageiras submetidas ao sombreamento se encontra diretamente relacionado com as alterações anatômicas, resultando em cutículas e epiderme mais delgadas, menor espessura de mesófilo, proporção de parênquima paliçádico reduzido e de tecidos condutores e de sustentação, maior proporção de espaços intercelulares além de menor densidade estomática (Figura 2) (BERLYN; CHO, 2000). 


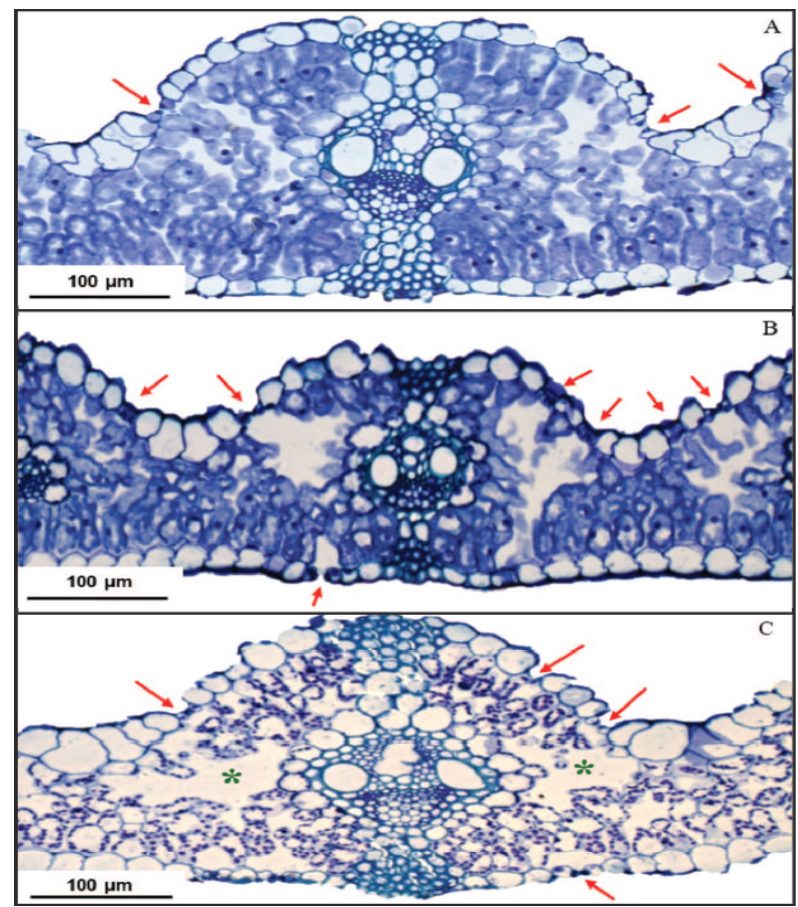

Figura 2. Aspecto geral do mesófilo de folha de azevém cultivado em pleno sol (A), em sub-bosque de angico-vermelho (B) e canafístula (C). Asteriscos indicam espaços intercelulares. Setas vermelhas indicam estômatos.

Fonte: Schmidt et al. (2017).

Do mesmo modo, Gobbi et al. (2011), correlacionando a área foliar específica e as características anatômicas foliares da Brachiaria decumbens $\mathrm{cv}$. Basilisk e do Arachis pintoi avaliadas em três níveis de sombreamento artificial (0, 50 e 70\%), observaram que a área foliar do Arachis pintoi e da Brachiaria decumbens apresentaram aumento linear devido ao incremento nos níveis de sombra, em média o aumento foi de 18 e 25\% nas plantas de Arachis pintoi e de 34 e $41 \%$ na Brachiaria decumbens, sob 50 e $70 \%$ de sombra, respectivamente.

Por isso, quando comparado o efeito de sombreamento a B. Brizantha apresenta, no mínimo, três vezes mais peso seco (g/planta) nas raízes do que outras espécies forrageiras (OLIVEIRA; SOUTO, 2001).

Assim, torna-se evidente que as características anatômicas são influenciadas, sobretudo, pelo estádio de desenvolvimento e pelo nível de inserção da folha 
no perfilho, além de variáveis ambientais como temperatura e intensidade de luminosidade (CARVALHO; PIRES, 2008).

Quadro 2. Levantamento sobre os estudos realizados referentes à morfologia de forrageiras submetidas ao sombreamento

\begin{tabular}{|c|c|c|}
\hline Autores (anatomia) & Estudos & Conclusões \\
\hline (NOBEL, 1980) & Lâmina foliar & $\begin{array}{l}\text { Sob o sombreamento tor- } \\
\text { nam-se mais finas }\end{array}$ \\
\hline $\begin{array}{l}\text { (BOSABALIDIS; KOFIDIS, 2002); (SILVA et al., } \\
\text { 2005) }\end{array}$ & Tricomas & $\begin{array}{l}\text { Redução da densidade, com } \\
\text { alterações no tamanho e } \\
\text { forma, presença ou ausência } \\
\text { dos mesmos }\end{array}$ \\
\hline (SILVA et al., 2005) & Nervuras foliares & Alterações \\
\hline $\begin{array}{l}\text { (LAMBERS; CHAPIM; PONS, 1998); (BERLYN; } \\
\text { CHO, 2000); (SILVA et al., 2005) }\end{array}$ & Estômatos & $\begin{array}{l}\text { Permanecem abertos por } \\
\text { mais tempo e consequente- } \\
\text { mente redução do número } \\
\text { e no tamanho dos mesmos }\end{array}$ \\
\hline (TAIZ; ZEIGER, 2009) & $\begin{array}{l}\text { Cloroplastos nas } \\
\text { células e lâmina } \\
\quad \text { foliar }\end{array}$ & $\begin{array}{l}\text { Movimento e disposição em } \\
\text { relação ao sol maximizando } \\
\text { a absorção de luz }\end{array}$ \\
\hline (BERLYN; CHO, 2000); (GOBBI et al., 2011) & Área foliar & $\begin{array}{l}\text { Aumento da área foliar } \\
\text { específica }\end{array}$ \\
\hline $\begin{array}{l}\text { (BERLYN; CHO, 2000); (BOSABALIDIS; KO- } \\
\text { FIDIS, 2002) }\end{array}$ & Mesófilo & Menor espessura \\
\hline (BERLYN; CHO, 2000) & $\begin{array}{l}\text { Parênquima } \\
\text { paliçádico }\end{array}$ & Redução \\
\hline $\begin{array}{l}\text { (OLIVEIRA; SOUTO, 2001); (GOBBI et al., } \\
\text { 2011) }\end{array}$ & $\begin{array}{c}\text { Forrageiras mais } \\
\text { adaptadas }\end{array}$ & $\begin{array}{l}\text { Brachiaria decumbens e } B . \\
\text { Brizantha }\end{array}$ \\
\hline
\end{tabular}

\subsection{FISIOLOGIA DE FORRAGEIRAS EM SISTEMAS AGROSSILVIPASTORIS}

Nos sistemas consorciados as espécies usadas se encontram em condição de competição por recursos. O potencial competitivo das plantas, pelos recursos do meio, varia em função da espécie presente na área do nível populacional (RIGOLI et al., 2008), e da época da emergência em relação a da cultura, além das características competitivas das cultivares (SILVA et al., 2009). 
Através da avaliação das alterações fisiológicas que ocorrem em plantas sob irradiância reduzida pode acarretar seleção de espécies forrageiras mais adaptadas a partir de técnicas de manejo compatíveis para obtenção de forragem de qualidade objetivando a manutenção da sustentabilidade do sistema produtivo (GOBBI et al., 2011).

Então, a escolha de espécies forrageiras sem dúvidas é um requisito fundamental a um sistema de produção sustentável, assim, referente aos aspectos fisiológicos a produtividade de Brachiaria brizantha cv. Marandu, sob diferentes níveis estruturais em sistema agrossilvipastoril utilizando eucalipto, reafirma que os arranjos desse sistema de produção praticamente não interferem no teor de fibras, nitrogênio e fósforo na forragem (OLIVEIRA et al., 2007). Visto que, quando submetidas ao sombreamento apresentam melhor qualidade, sobretudo maior teor de proteína bruta na lâmina foliar e maior relação lâmina foliar: colmo, entretanto a produção de matéria seca seja mais reduzida com a presença de árvores (SOARES et al., 2009).

Resultados semelhantes foram obtidos por Paciullo et al. (2007), em condições de sombreamento em sistema silvipastoril, provoca alterações fisiológicas em $B$. decumbens, contribuindo para o aumento da interceptação da radiação fotossinteticamente de luz. Tal sistema também contribui para aumento dos teores de proteína bruta e redução dos teores de fibra em detergente neutro, e incrementa a digestibilidade in vitro da matéria seca da $B$. decumbens, cultivada em sistemas agroflorestais.

O sombreamento proporciona, respectivamente, incrementos de 28 e $12 \%$ no percentual de proteína bruta e digestibilidade in vitro da matéria seca das folhas da forrageira. Em áreas onde são encontradas árvores e pastagem, os animais preferem pastejar sob as árvores, na sombra, e, nessa condição, ocorre maior ganho de peso (PIRES et al., 2007).

Entretanto, o uso mais eficiente da água está diretamente relacionado ao tempo de abertura estomática, pois, enquanto a planta absorve $\mathrm{CO}_{2}$, a água é perdida pela transpiração, com intensidade variável, dependendo do gradiente de potencial entre a superfície foliar e a atmosfera (CONCENÇO et al., 2008).

Diante de tal fato, o cultivo de capim-andropógon em sistema silvipastoril, composto pelas espécies arbóreas pau-d'arco e jatobá, se mostra bastante viável por 
não ocorrer alterações na composição de MS e FDA e proporção de NIDN e NIDA na planta e nas folhas, sobretudo nos teores de PB na planta e de FDN nas folhas se mantêm estáveis, visto que há maior teor de PB nas folhas da gramínea em sistemas silvipastoris. Inclusive o teor de FDN da gramínea se manteve independente e paralelo ao ambiente, em função da idade de rebrota (LACERDA et al., 2009).

Em relação à fotossíntese, respiração e transpiração de cultivares submetidas ao sombreamento da mesma espécie forrageira e do mesmo gênero podem diferenciar quanto à densidade de estômatos. Visto que um dos aspectos fisiológicos bastante característicos referentes a forrageiras são os estômatos, dos quais são identificados como a porta de entrada e escoamento dos gases para a realização da fotossíntese, processo esse que é primordial relacionado à produtividade vegetal, contudo pode variar a partir de diferentes espécies de plantas o número, frequência, tamanho, distribuição, forma e a mobilidade dos estômatos, ocorrendo interferência na capacidade fotossintética (SILVA et al., 2005).

Igualmente para Dias-Filho (2002), avaliando respostas fotossintéticas do capim-marandu e do capim quicuio-da-amazônia em casa de vegetação sob sombreamento artificial, identificou que as duas espécies forrageiras são capazes de se ajustar ao comportamento fotossintético sob sombreamento, com maior destaque devido a adaptação do quicuio-da-amazônia.

Já em períodos chuvosos sob sombreamento o Arachis pintoi cv. Belmonte é uma leguminosa bastante produtiva a níveis de sombreamento até 50\% de sombra, com produção próxima aos capins marandu e massai no mesmo sistema de produção (ANDRADE et al., 2004).

Do mesmo modo avaliando o comportamento fisiológico das gramíneas forrageiras tropicais submetidas ao sombreamento, referentes as respostas fotossintéticas e os teores de clorofila comparados em plantas cultivadas em solo natural, em vasos, a pleno sol e a 70\% de interceptação da luz solar, as duas espécies forrageiras Brachiaria brizantha cv. Marandu e B. bumidicola se mostraram capazes de ajustar o comportamento fotossintético ao sombreamento. Entretanto a respiração no escuro e a razão clorofila a:b se mostraram significativamente reduzidas pelo sombreamento somente em $B$. humidicola, considerando que essa última poderia ser relativamente mais adaptada a ambientes sujeitos a redução temporária de luz 
(DIAS-FILHO, 2002).

Dessa forma, avaliando o sombreamento no crescimento inicial de gramíneas forrageiras tropicais na Embrapa Agrobiologia, localizada na cidade de Seropédica (RJ), nos níveis de 25,50 e $75 \%$, referente a produção de matéria seca da parte aérea, além dos índices de área foliar, as espécies $B$. brizantha cr. Marandu e o Pennisetum purpurem cv. Cameron apresentam significativo crescimento inicial até o nível de $75 \%$ de sombreamento, indicando que em condições de sombreamento mais severo, essas espécies são capazes de apresentar um bom desenvolvimento (OLIVEIRA; SOUTO, 2001).

Avaliando o efeito no nível de sombreamento artificial de 0, 30, 50 e 70\%, nas taxas de acúmulo de matéria seca de quatro gramíneas e três leguminosas forrageiras em Rio Branco (AC), observou-se que os capins marandu e massai apresentaram o melhor desempenho entre as gramíneas, com e alta capacidade produtiva sob condições de sombreamento em solos bem drenados. Ao contrário do quicuio-da-amazônia que apresentou menor tolerância ao sombreamento, visto que, por ser usado em sistemas silvipastoris com baixa densidade arbórea. Já o capim-pensacola demonstrou alta tolerância ao sombreamento, entretanto, baixa capacidade produtiva. E o Arachis pintoi cv. Belmonte apresentou alta capacidade produtiva e tolerância ao sombreamento que as demais leguminosas em estudo (ANDRADE et al., 2004).

Analisando os efeitos da restrição de luminosidade, a partir de diferentes densidades de árvores e a qualidade de leguminosas em três níveis de luminosidade, em sol aberto sem presença de árvores, 30\% de restrição de radiação e 60\% de restrição de radiação, observou-se que o azevém apresentou maior produção em todos os níveis de luminosidade, e maior umidade no solo nos ambientes sombreados, entretanto a produção de forragem, a composição química e os componentes reduziram significativamente no sombreamento mais intenso a 81\% (KIRCHNER et al., 2010).

O comportamento de espécies forrageiras submetidas a diferentes níveis de luminosidade produzidos por árvores a céu aberto a $9 \mathrm{~m}$ entre linhas e $3 \mathrm{~m}$ entre árvores, e 15 m entre linhas e 3 m entre árvores, apresenta que as espécies Brachiaria brizantha cv. Marandu e Axonopus catharinensis apresentam produções significativas e se destacam quanto à produtividade e adaptação ao sombreamento, 
visto que o maior espaçamento, de $15 \times 3 \mathrm{~m}$, proporciona melhores condições para o crescimento e qualidade da forragem (SOARES et al., 2009).

Quadro 3. Levantamento sobre os estudos realizados referentes à morfologia de forrageiras submetidas ao sombreamento

\begin{tabular}{|c|c|c|}
\hline Autores (Fisiologia) & Estudos & Conclusões \\
\hline $\begin{array}{l}\text { (OLIVEIRA; SOUTO, 2001); (DIAS-FILHO, } \\
\text { 2002); (ANDRADE et al., 2004); (OLIVEIRA et } \\
\text { al., 2007); (SOARES et al., 2009); (GOBBI et } \\
\text { al., 2011) }\end{array}$ & $\begin{array}{l}\text { Forrageiras mais } \\
\text { adaptadas }\end{array}$ & $\begin{array}{l}\text { Brachiaria brizantha cv. } \\
\text { Marandu; } B \text {. decumbens }\end{array}$ \\
\hline $\begin{array}{l}\text { (OLIVEIRA et al., 2007); (PACIULLO et al., } \\
\text { 2007); (PIRES et al., 2007); (LACERDA et al., } \\
\text { 2009); (SOARES et al., 2009) }\end{array}$ & $\begin{array}{l}\text { Teor de fibras, ni- } \\
\text { trogênio e fósforo } \\
\text { na forragem }\end{array}$ & $\begin{array}{l}\text { Sem alterações prejudiciais. } \\
\text { Já o teor de fibra pode } \\
\text { reduzir propiciando o incre- } \\
\text { mento da digestibilidade in } \\
\text { vitro da matéria seca }\end{array}$ \\
\hline $\begin{array}{l}\text { (PACIULLO et al., 2007); (PIRES et al., 2007); } \\
\text { (SOARES et al., 2009); (LACERDA et al., 2009) }\end{array}$ & $\begin{array}{l}\text { Proteína bruta na } \\
\text { lâmina foliar }\end{array}$ & $\begin{array}{l}\text { Melhor qualidade, sobretu- } \\
\text { do maior teor de proteína }\end{array}$ \\
\hline $\begin{array}{l}\text { (ANDRADE et al., 2004); (SOARES et al., } \\
\text { 2009); (SOARES et al., 2009); (KIRCHNER et } \\
\text { al., 2010) }\end{array}$ & Folha: colmo & Maior proporção de folha \\
\hline $\begin{array}{l}\text { (OLIVEIRA; SOUTO, 2001); (ANDRADE et al., } \\
\text { 2004); (PIRES et al., 2007); (SOARES et al., } \\
\text { 2009); (LACERDA et al., 2009) }\end{array}$ & Matéria seca & Reduz \\
\hline (PIRES et al., 2007) & $\begin{array}{l}\text { Ganho de peso } \\
\text { bovinos }\end{array}$ & $\begin{array}{l}\text { Maior ganho de peso quan- } \\
\text { do os animais pastejam sob } \\
\text { o sombreamento }\end{array}$ \\
\hline (SILVA et al., 2005); (CONCENÇO et al., 2008) & Estômatos & $\begin{array}{l}\text { Maior perda de água por } \\
\text { transpiração, com altera- } \\
\text { ções na mobilidade }\end{array}$ \\
\hline (DIAS-FILHO, 2002); (SILVA et al., 2005) & Fotossíntese & $\begin{array}{l}\text { Interferência negativa na } \\
\text { capacidade fotossintética } \\
\text { de forrageiras sob níveis de } \\
\text { sombreamento elevado }\end{array}$ \\
\hline (DIAS-FILHO, 2002) & Clorofila & Redução da clorofila a:b \\
\hline $\begin{array}{l}\text { (OLIVEIRA; SOUTO, 2001); (DIAS-FILHO, } \\
\text { 2002); (ANDRADE et al., 2004); (SOARES et } \\
\text { al., 2009); (KIRCHNER et al., 2010) }\end{array}$ & $\begin{array}{l}\text { Nível de sombrea- } \\
\text { mento }\end{array}$ & $\begin{array}{l}\text { Acima de } 75 \% \text { interferem } \\
\text { negativamente na fisiologia } \\
\text { de forrageiras }\end{array}$ \\
\hline
\end{tabular}




\section{CONSIDERAÇÕES FINAIS}

A partir da realização dessa pesquisa, referente aos aspectos morfológicos, pode-se constatar que há um aumento na área foliar de forrageiras sob sombreamento a fim de maximizar a captação da luz e consequentemente maior densidade de massa forrageira. Para os aspectos anatômicos há redução no número e tamanho dos estômatos, além da lâmina foliar se tornar menos espessa. Já para a fisiologia, nota-se que há aumento na qualidade da forragem com elevação no teor de proteína bruta com maior relação folha-colmo, além da redução no teor de fibra. De maneira ampla, dentre as espécies forrageiras analisadas, a Brachiaria brizantha cv. Marandu é a que mais se destaca para o uso em sistema agrossilvipastoril, devido seu elevado desempenho mesmo em níveis de sombreamentos de mais de 75\%.

\section{REFERÊNCIAS}

ANDRADE, C. M. S.; GARCIA, R.; COUTO, L.; PEREIRA, O. G.; SOUZA, A. L. Desempenho de Seis Gramíneas Solteiras ou Consorciadas com o Stylosanthes guianensis cv. Mineirão e Eucalipto em Sistema Silvipastoril. Revista Brasileira de Zootecnia, v. 32, n. 6, p. 1845-1850, 2003.

ANDRADE, C. M. S.; VALENTIM, J. F.; CARNEIRO, J. C.; VAZ, F. A. Crescimento de gramíneas e leguminosas forrageiras tropicais sob sombreamento. Pesquisa Agropecuária Brasileira. Brasília, v. 39, n. 3, p. 263-270, 2004.

APPEZZATO-da-GLORIA, B.; CARMELLO-GUERREIRO, S. M. Anatomia Vegetal. Editora da Universidade Federal de Viçosa. Viçosa-MG. 2006.

BERLYN, G. P.; CHO, J. Light, moisture, and nutrient use by plants. In: ASHTON, M. S.; MONTAGNINI, F. The silvicultural basis for agroforestry systems. (Eds.), Boca Raton: CRC Press, 2000. p. 9-39. 
BOSABALIDIS, A. M.; KOFIDIS, G. Comparative effects of drought stress on leaf anatomy of two olive Cultivars. Plant Science, 163: 375-379, 2002.

BOSI, C.; PEZZOPANE, J. R. M.; SENTELHAS, P. C.; SANTOS, P. M.; NICODEMO, M. L. F. Produtividade e características biométricas do capim-braquiária em sistema silvipastoril. Pesquisa Agropecuária Brasileira, Brasília, v. 49, n. 6, p. 449-456, 2014.

BOTREL, R. T.; OLIVEIRA FILHO, A. T.; RODRIGUES, L. A.; CURI, N. Influência do solo e topografia sobre as variações da composição florística e estrutura da comunidade arbóreo-arbustiva de uma floresta estacional semi decidual em Ingaí-MG. Revista Brasileira de Botânica, v. 25, n. 2, p. 195-213, 2002.

CARVALHO, G. G. P.; PIRES, A. J. V. Organização dos Tecidos de Plantas Forrageiras e suas Implicações para os Ruminantes. Revista Archivos de Zootecnia, p. 13-28, 2008.

CASTRO, K. J.; NEIVA, J. N. M.; FALCAO, A. J. D.; MIOTTO, F. R. C.; OLIVEIRA, R. C. Behavior responses of dairy heifers fed with byproducts based diets. Revista Ciência Agronômica, 40: 306-314, 2009.

CONCENÇO, G.; FERREIRA, E. A.; SILVA, A. A.; FERREIRA, F. A.; GALON, L.; REIS, M. R.; D’ANTONINO, L.; VARGAS, L.; SILVA, L. V. B. D. Fotossíntese de biótipos de azevém sob condição de competição. Planta Daninha, Viçosa, v. 26, n. 3, p. 595600, 2008.

CONFORTO, E. C.; BITTENCOURT JUNIOR, N. S.; SCALOPPI JUNIOR, E. J.; MOREIRA, R. M. B. Comparação entre folhas sombreadas de sete clones adultos de seringueira. Revista Ceres, Viçosa, v. 58, n. 1, p. 29-34, 2011.

DIAS-FILHO, M. B. Photosynthetic light response of the C4 grasses Brachiaria brizantha and B. bumidicola under shade. Scientia Agricola, v. 59, p. 65-68, 2002. 
DIAS-FILHO, M. B. Sistemas silvipastoris na recuperação de pastagens tropicais degradadas. In: GONZAGA NETO, S.; COSTA, R. G.; PIMENTA FILHO, E. C.; COSTA, J. M. da C. (Eds). Simpósio da Reunião Anual da Sociedade Brasileira de Zootecnia. 43. João Pessoa. Anais... v. 35, p. 535-553, 2006.

DIAS, P. F.; SOUTO, S. M.; AZEVEDO, B. C.; VIEIRA, M. S.; COLOMBARI, A. A.; DIAS, J.; FRANCO, A. A. Estabelecimento de leguminosas arbórea sem pastos de capim-marandu e Tanzânia. Pesquisa Agropecuária Brasileira, Brasília, v. 43, n. 10, p. 1413-1419, 2008.

DIGNART, S. L.; CASTRO, E. M.; PASQUAL, M.; FERRONATO, A.; BRAGA, F. T.; PAIVA, R. Luz natural e concentrações de sacarose no cultivo in vitro de Cattleya walkeriana. Ciência e Agrotecnologia, Lavras, v. 33, n. 3, p. 780-787, 2009.

FAO - Organização das Nações Unidas para a Alimentação e Agricultura. Perspectivas para a produção mundial de carnes. 2014. Disponível em: < https://editorastilo. com.br/revista-graxaria/item/1708-fao-perspectivas-para-a-producao-mundial-de-carnes $>$. Acesso em: 14 jan. 2016.

GARCEZ NETO, A. F.; GARCIA, R.; MOOT, D. J.; GOBBI, K. F. Aclimatação morfológica de forrageiras temperadas a padrões e níveis de sombreamento. Revista Brasileira de Zootecnia, v. 39, n. 1, p. 42-50, 2010.

GOBBI, K. F.; GARCIA, R.; VENTRELLA, M. C.; GARCEZ NETO, A. F.; ROCHA, G. C. Área foliar específica e anatomia foliar quantitativa do capim-braquiária e do amendoim-forrageiro submetidos a sombreamento. Revista Brasileira de Zootecnia, v. 40, n. 7, p. 1436-1444, 2011.

KIRCHNER, R.; SOARES, A. B.; SARTOR, L. R.; ADAMI, P. F.; MIGLIORINI, F.; FONSECA, L. Desempenho de forrageiras hibernais sob distintos níveis de luminosidade. Revista Brasileira de Zootecnia, v. 39, n. 11, p. 2371-2379, 2010. 
LACERDA, M. S. B.; ALVES, A. A.; OLIVEIRA, M. E.; ROGERIO, M. C. P.; CARVALHO, T. B.; VERAS, V. S. Composição bromatológica e produtividade do capim-andropógon em diferentes idades de rebrota em sistema silvipastoril. Acta Scientiarum. Animal Sciences. Maringá, v. 31, n. 2, p. 123-129, 2009.

LAMBERS, H.; CHAPIM III, F. S.; PONS, T. L. Plant physiological ecology. New York: Springer, 540p. 1998.

MARTUSCELLO, J. A. Influência da Anatomia e da Morfologia na Qualidade de Gramíneas Forrageiras Tropicais. Forragicultura e Pastagem. 2004.

MARTUSCELLO, J. A.; JANK, L.; GONTIJO NETO, M. M.; LAURA, V. A.; CUNHA, D. N. F. V. Produção de gramíneas do gênero Brachiaria sob níveis de sombreamento. Revista Brasileira de Zootecnia, v. 38, n. 7, p. 1183-1190, 2009.

NOBEL, P. S. Leaf anatomy and water use efficiency. In: TURNER, N. C.; KRAMER, P. J. Adaptation of Plants to Water and High Temperature Stress. New York: Wiley. (eds.). p. 43-55, 1980.

OLIVEIRA, F. L.; SOUTO, S. M. Efeito no Sombreamento no Crescimento Inicial de Gramíneas Forrageiras Tropicais. Pesquisa Agropecuária Gaúcha, v. 7, n. 2, p. 221226, 2001.

OLIVEIRA, T. K.; MACEDO, R. L. G.; SANTOS, Í. P. A.; HIGASHIKAWA, E. M.; VENTURIN, N. Produtividade de Brachiaria Brizantha (Hochst. Ex A. Rich.) Stapf cv. Marandu sob Diferentes Arranjos Estruturais de Sistema Agrossilvipastoril com Eucalipto. Ciência e Agrotecnologia, Lavras, v. 31, n. 3, p. 748-757, 2007.

OLIVEIRA, P. D. de; MANESCHY, R. Q. Sistemas agroflorestais pecuários com ênfase nas espécies arbóreas e/ou arbustivas forrageiras. Revista Agroecossistemas, v. 1, n. 1, p. 21-21, 2009. 
PACIULLO, D. S. C.; CARVALHO, C. A. B.; AROEIRA, L. J. M.; MORENZ, M. J. F.; LOPES, F. C. F.; ROSSIELLO, R. O. P. Morfofisiologia e valor nutritivo do capim-braquiária sob sombreamento natural e a sol pleno. Pesquisa Agropecuária Brasileira, v. 42, n. 4, p. 573-579, 2007.

PACIULLO, D. S. C.; CAMPOS, N. R.; GOMIDE, C. A. M.; CASTRO, C. R. T.; TAVELA, R. C.; ROSSIELLO, R. O. P. Crescimento de capim-braquiária influenciado pelo grau de sombreamento e pela estação do ano. Pesquisa Agropecuária Brasileira, Brasília, v. 43, n. 7, p. $917-923,2008$.

PACIULLO, D. S. C.; GOMIDE, C. A. M.; CASTRO, C. R. T.; FERNANDES, P. B.; MÜLLER, M. D.; PIRES, M. F. Á.; FERNANDES, E. N.; XAVIER, D. F. Características produtivas e nutricionais do pasto em sistema agrossilvipastoril, conforme a distância das árvores. Pesquisa Agropecuária Brasileira, v. 46, n. 10, p. 1176-1183, 2011.

PERI, P. L.; LUCAS, R. J.; MOOT, D. J. Dry matter production, morphology and nutritive value of Dactylis glomerata growing under different light regimes. Agroforestry Systems, v. 70, p. 63-79, 2007.

RIGOLI, R. P.; AGOSTINETTO, D.; SCHAEDLER, C. E.; DAL MAGRO, T.; TIRONI, S. Habilidade competitiva relativa do trigo (Triticum aestivum) em convivência com azevém (Lolium multiflorum) ou nabo (Raphanus raphanistrum). Planta Daninha, Viçosa, v. 26, n. 1, p. 93-100, 2008.

SCHMIDT, D.; CARON, B. O.; PILAU, J.; NARDINO, M. Morfoanatomia foliar de azevém no sub-bosque de espécies arbóreas em sistemas agroflorestais. Revista Ceres, v. 64, n. 4 , p. 368-375, 2017.

SILVA, L. M.; ALQUINI, Y.; CAVALLET, V. J. Inter-relações entre a anatomia vegetal e a produção vegetal. Acta Botanica Brasilica, v. 19, n. 1, p. 183-194, 2005. 
SILVA, A. C.; FREITAS, R. S.; FERREIRA, L. R.; FONTES, P. C. R. Acúmulo de macro e micronutrientes por soja e Brachiaria brizantha emergida em diferentes épocas. Planta daninha, Viçosa, v. 27, n. 1, p. 49-56, 2009.

SILVA, C. C. M. F.; ROSSIELLO, R. O. P.; PACIULLO, D. S. C.; GOMES, D. M. S.; CARVALHO, C. A. B.; RIBEIRO, R. C. Atributos morfofisiológicos e fitomassa de Brachiaria decumben sem um sistema silvipastoril. Revista de Ciência Vida, Rio de Janeiro, v. 31, n. 2, p. 94-101, 2011.

SOARES, A. B.; SARTOR, L. R.; ADAMI, P. F.; VARELLA, A. C.; FONSECA, L.; MAZZALIRA, J. C. Influência da luminosidade no comportamento de onze espécies forrageiras perenes de verão. Revista Brasileira de Zootecnia, v. 38, n. 3, p. 443-451, 2009.

TAIZ, L.; ZEIGER, E. Fisiologia Vegetal. $4^{\mathrm{a}}$ ed. Porto Alegre: Artmed. p. 145-315, 2009.

VERAS, V. S.; OLIVERIA, M. E.; LACERDA, M. S. B.; CARVALHO, T. B.; ALVES, A. A. Produção de biomassa e estrutura do pasto de capim-andropogon em sistema silvipastoril e monocultura. Arquivo Brasileiro de Medicina Veterinária e Zootecnia, v. 62 , n. 1, p. 200-207, 2010.

WEDEKIN, I. Economia da pecuária de corte: fundamentos e o ciclo de preços. São Paulo: Wedekin Consultores. p. 180, 2017.

WENDLING, I. J. Produtividade e valor nutritivo do capim-braquiária em sistemas silvipastoris com Eucalipto e Acácia adubados com nitrogênio. 2011. $95 \mathrm{f}$. Tese (Doutorado em Zootecnia) - Universidade Federal de Viçosa, Viçosa, MG, 2011.

Recebido em: 07/03/2016 Aceito em: 12/11/2017 